\title{
Kinetic Analysis of Pseudomonas aeruginosa Arginine Deiminase Mutants and Alternate Substrates Provides Insight into Structural Determinants of Function ${ }^{\dagger}$
}

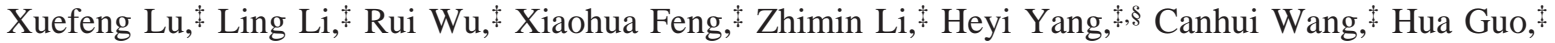 \\ Andrey Galkin," Osnat Herzberg," Patrick S. Mariano, ${ }^{\ddagger}$ Brian M. Martin, ${ }^{\perp}$ and Debra Dunaway-Mariano*,\$ \\ Department of Chemistry, University of New Mexico, Albuquerque, New Mexico 87131, Center for Advanced Research in \\ Biotechnology, University of Maryland Biotechnology Institute, 9600 Gudelsky Drive, Rockville, Maryland 20850, and \\ Molecular Structure Unit, Laboratory of Neurotoxicology, NIMH, Building 10, Room 3N309, 10 Center Drive, MSC 1262, \\ Bethesda, Maryland 20892-1262
}

Received August 10, 2005; Revised Manuscript Received November 29, 2005

\begin{abstract}
L-Arginine deiminase from Pseudomonas aeruginosa (PaADI) catalyzes the hydrolysis of arginine to citrulline and ammonia. PaADI belongs to the guanidino group-modifying enzyme superfamily (GMSF), which conserves backbone fold and a Cys-, His-, and Asp-based catalytic core. In this paper the contributions made by the PaADI core residues Cys406, His278, and Asp166 and the contribution from the neighboring Asp280 (conserved in most but not all GMSF members) to catalysis of the formation and hydrolysis of the Cys406-alkyluronium intermediate were accessed by kinetic analysis of site-directed mutants. In addition, solution hydrolysis in a chemical model of the $S$-alkylthiouronium intermediate was examined to reveal the importance of general base catalysis in the enzymatic reaction. Substitutions of the active site gating residue $\mathrm{Arg} 401$, the L-arginine $\mathrm{C}^{\alpha} \mathrm{NH}_{3}{ }^{+}\left(\mathrm{COO}^{-}\right)$binding residues, $\operatorname{Arg} 185, \operatorname{Arg} 243$, and Asn160, or the His278 hydrogen bond partner, Glu224, were found to cause dramatic reductions in the enzyme turnover rate. These results are interpreted to suggest that electrostatic interactions play a dominant role in PaADI catalysis. Structural variations observed in P. aeruginosa GMSF enzymes PaADI, agmatine deiminase (PaAgDI), and $N^{\omega}, N^{\omega}$-dimethylarginine dimethylaminohydrolase (PaDDAH) indicate an early divergence of the encoding genes. Arginine analogues that are known substrates for PaAgDI and $\mathrm{PaDDAH}$ were tested with PaADI to define clear boundaries of biochemical function in the three hydrolases. The conservation of a catalytic core associated with the common chemical function and the divergence of substrate-binding residues (as well as one key catalytic residue) to expand the substrate range provide insight into the evolution of the catalysts that form the GMSF.
\end{abstract}

The guanidino-modifying enzyme superfamily (hereafter referred to as the GMSF) ${ }^{1}$ is a large family of $\alpha / \beta$-propellerfold enzymes that catalyze nucleophilic substitution reactions at the guanidinium carbon atom of L-arginine or an L-arginine derivative (for an excellent review, see ref 1 ). The family is divided into the hydrolase branch, in which an external guanidino $\mathrm{NH}_{2}$ group is displaced, and the transferase branch, in which the ornithine moiety is displaced. The most remarkable family member, $N$-succinylarginine dihydrolase

†Supported by NIH Grants GM28688 (D.D.-M.), GM57890 (O.H.), AI59733 (O.H., D.D.-M., P.S.M.), by NSF Grant MCB-30370337 (H.G.), and by the Intramural Research Program of the NIH, NIMH (B.M.M.).

* Corresponding author. Tel: 505-277-338. Fax: 505-277-6202. E-mail: dd39@unm.edu.

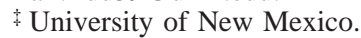

$\S$ Current address: Albert Einstein School of Medicine.

"University of Maryland Biotechnology Institute.

${ }^{\perp}$ Laboratory of Neurotoxicology, NIMH.

${ }^{1}$ Abbreviations: GMSF, guanidino-modifying enzyme superfamily; $\mathrm{Pa}$, Pseudomonas aeruginosa; $\mathrm{K}^{+} \mathrm{Mes}$, potassium salt of $2-(\mathrm{N}$-morpholino)ethanesulfonate; Bis-Tris- $\mathrm{HCl}$, [bis(2-hydroxyethyl)amino]tris(hydroxymethyl)methane; $\mathrm{K}^{+}$Hepes, potassium salt of $N$-(2-hydroxyethyl)piperazine- $N^{\prime}$-2-ethanesulfonate; $\mathrm{K}^{+}$Taps, potassium salt of 3-[[tris(hydroxymethyl)methyl]amino]propanesulfonate; ADI, arginine deiminase; AgDI, agmatine deiminase; DDAH, dimethylarginine dimethylaminohydrolase.
(2), catalyzes two consecutive substitution reactions, thus combining the elements of both branches. Aside from $\mathrm{N}$-succinylarginine dihydrolase (3), the genome of Pseudomonas aeruginosa encodes three chemical homologues of the hydrolase branch of the GMSF: arginine deiminase (accession number P13981; locus name PA5171) (PaADI), agmatine deiminase (accession number Q9I6J9; locus name PA0292) (PaAgDI), and $N^{\omega}, N^{\omega}$-dimethylarginine dimethylaminohydrolase (accession number Q9I4E3; locus name PA1195) (PaDDAH). A comparison of the published PaADI (4) and PaDDAH (5) X-ray structures with the recently deposited structure of the AgADI from Arabidopsis thaliana (PDB code 1VKP) (6) demonstrates that despite their low pairwise sequence identity $(<15 \%)$ the three hydrolases share a common backbone fold and catalytic scaffold. An overlay of the structures of PaADI and PaDDAH is depicted in Figure 1 to show that even though the PaDDAH is significantly smaller than PaADI, the active site frame is well conserved.

As is illustrated in Figure 2, the chemical reactions catalyzed by PaADI, PaAgDI, and PaDDAH are similar in that each entails the hydrolytic cleavage of one of the two external amino substituents of the guanidino group in L-arginine or its derivative (Figure 2). PaADI catalyzes the 
(A)
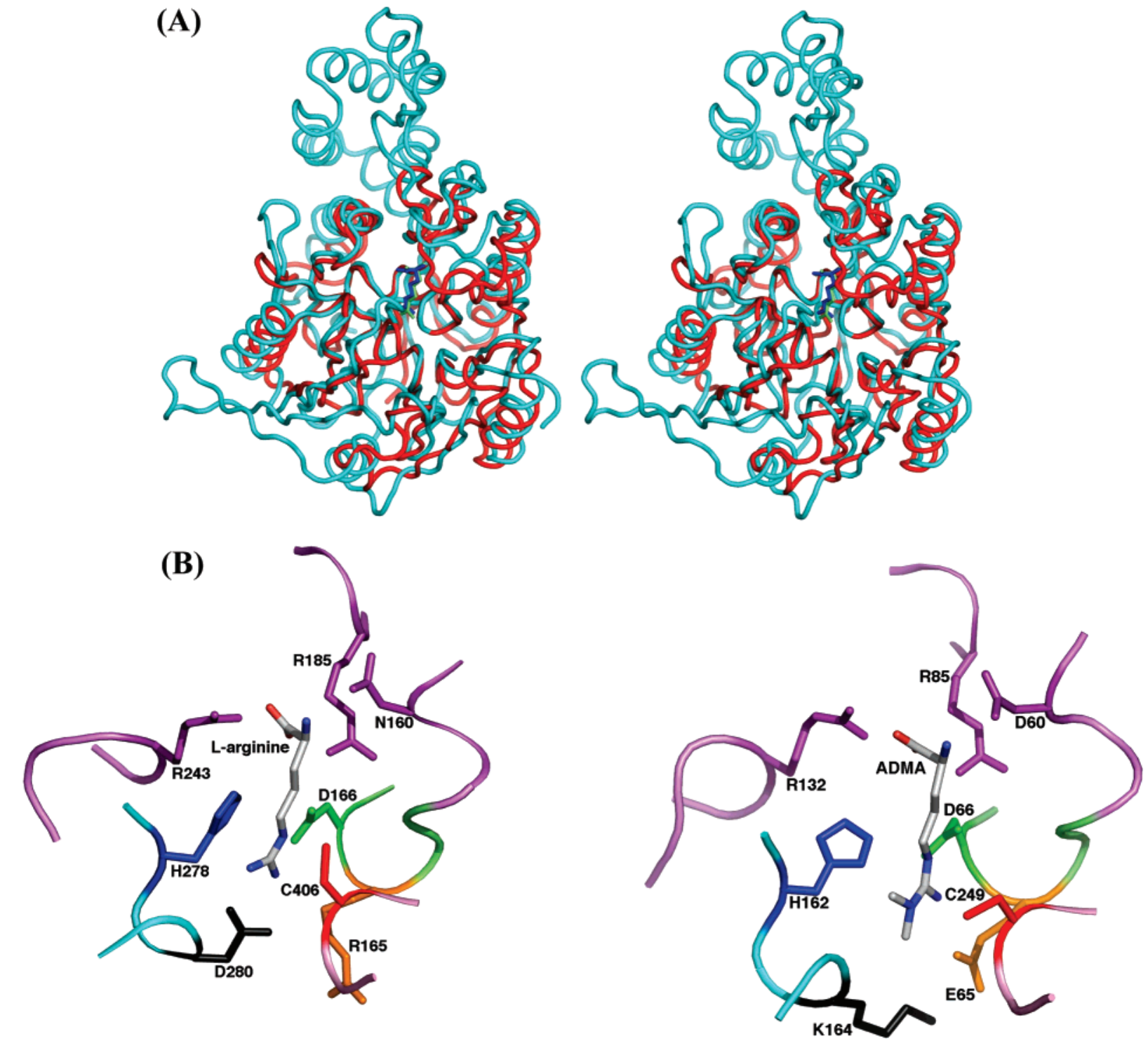

FIGURE 1: (A) Stereo diagram of the backbone structures of PaADI (cyan) with the L-arginine ligand (blue) and PaDDAH (red) with the L-citrulline ligand (green). Figures were generated using Pymol and the X-ray coordinates of the C406A PaADI-L-arginine complex (20) and the PaDDAH-L-citrulline complex (5). (B) Comparison of the active sites of PaADI (left) and PaDDAH (right). The residues that bind the substrate $\mathrm{C}^{\alpha}-\mathrm{COO}^{-}$substituent are in pink. The core residues are Cys (red), His (blue), and Asp (green). The swapped residues are PaADI Asp280 (black) and Arg156 (orange) vs PaDDAH Lys164 (black) and Glu64 (orange).
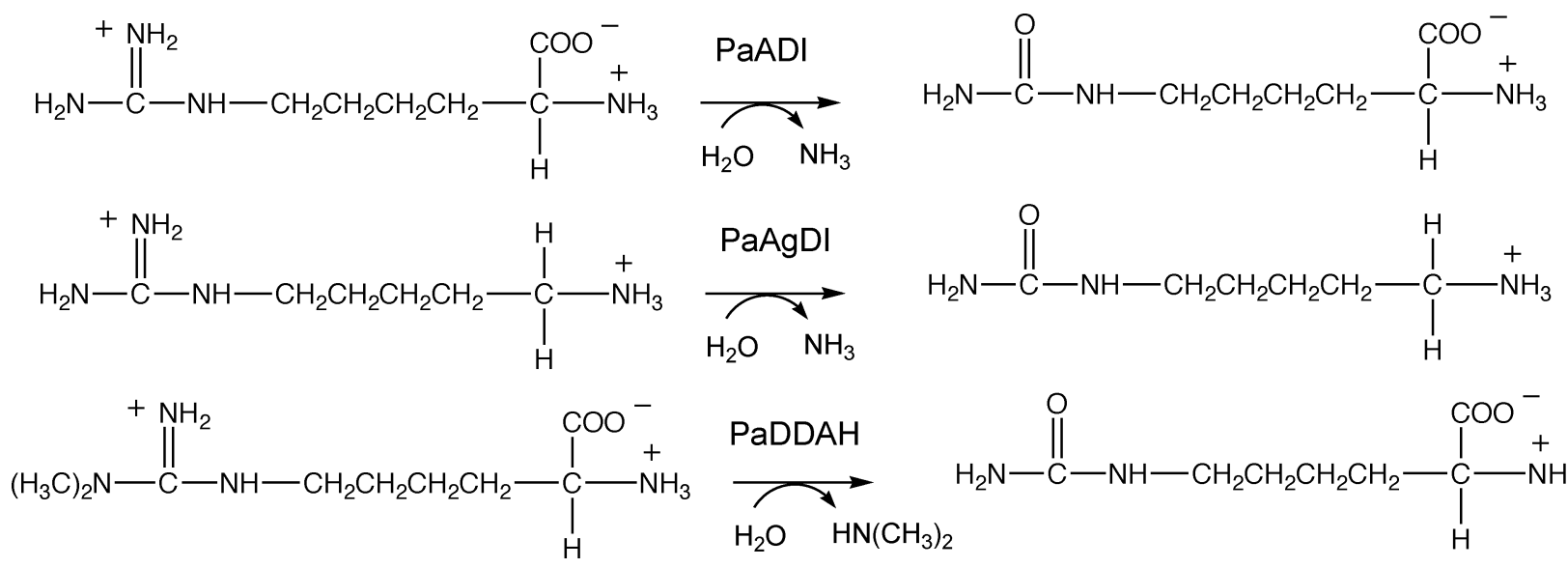<smiles>NC(=O)NCCCCC([NH3+])[O-]</smiles>

Figure 2: Chemical reactions catalyzed by PaADI, PaAgDI, and PaDDAH in the cell.

hydrolysis of L-arginine to citrulline and ammonia (7), $\mathrm{PaAgDI}$ catalyzes the hydrolysis of agmatine to form ammonia and $\mathrm{N}$-carbamoylputrescine (8), and PaDDAH catalyzes the hydrolysis of $N^{\omega}, N^{\omega}$-dimethylarginine to dimethylamine and citrulline $(9,10)$. As is the case with all members of the GMSF, these deiminases conserve a catalytic 


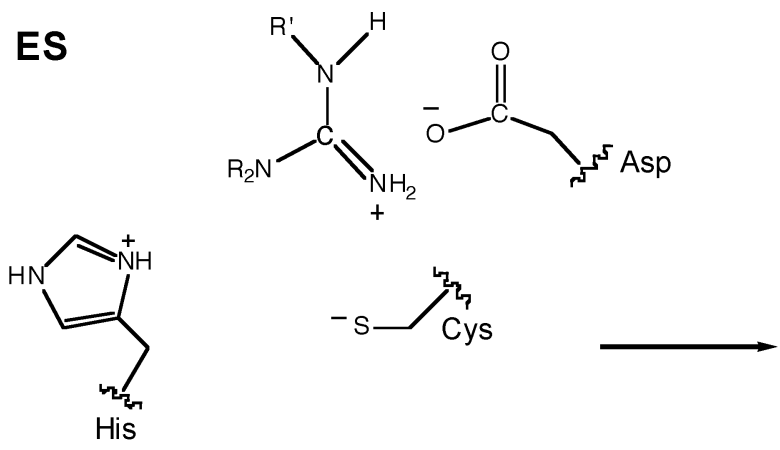

S-Akyluronimium Intermediate
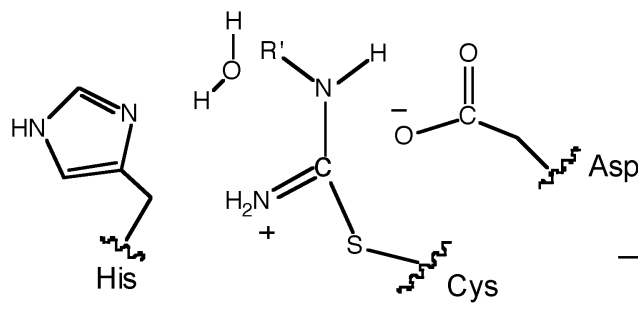

Tetrahedral Intermediate I

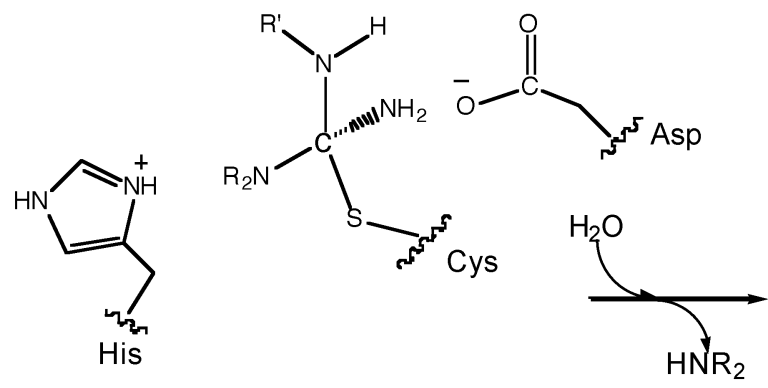

Tetrahedral Intermediate II

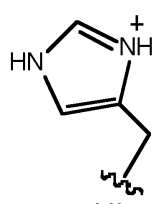

His

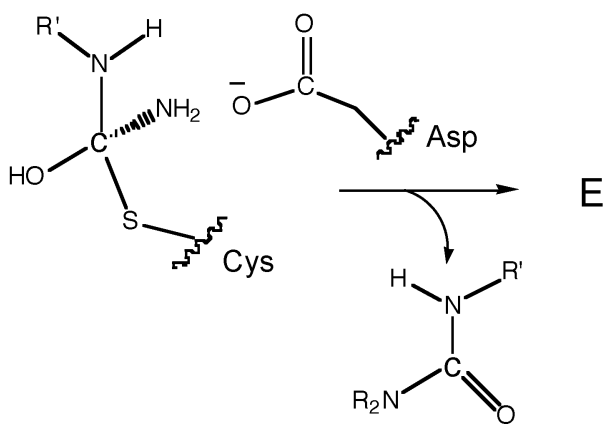

FIgure 3: A model for the function of the core catalytic residues Cys, His, and Asp in PaADI, PaAgDI, and PaDDAH catalysis. The residues and substrate shown are Cys401, His278, and Asp166, $\mathrm{R}^{\prime}=\left(\mathrm{CH}_{2}\right)_{3} \mathrm{C}(\mathrm{H})\left(\mathrm{NH}_{3}{ }^{+}\right)\left(\mathrm{COO}^{-}\right), \mathrm{R}=\mathrm{H}$ in PaADI; Cys249, His162, and Asp66, $\mathrm{R}^{\prime}=\left(\mathrm{CH}_{2}\right)_{3} \mathrm{C}(\mathrm{H})\left(\mathrm{NH}_{3}{ }^{+}\right)\left(\mathrm{COO}^{-}\right), \mathrm{R}=\mathrm{CH}_{3}$ in PaDDAH; Cys357, His217, and Asp94, $\mathrm{R}^{\prime}=\left(\mathrm{CH}_{2}\right)_{3} \mathrm{CH}_{2}\left(\mathrm{NH}_{3}{ }^{+}\right), \mathrm{R}=\mathrm{H}_{\text {in }} \mathrm{PaAgDI}$; and Cys366, His224, and Asp94, $\mathrm{R}^{\prime}=\left(\mathrm{CH}_{2}\right)_{3} \mathrm{CH}_{2}\left(\mathrm{NH}_{3}{ }^{+}\right), \mathrm{R}=\mathrm{H}$ in AtAgDI.

Cys residue which functions in nucleophilic catalysis, a His residue that might function in acid/base catalysis, and an Asp residue that is oriented to bind the substrate guanidino group $(5,10,11)$. These "core" catalytic residues ${ }^{2}$ are identically positioned on the catalytic scaffolds of the individual GMSF members and are therefore assumed to mediate the common chemistry that is catalyzed (see Figure 3).

The biochemical connection that exists between PaADI, $\mathrm{PaAgDI}$, and PaDDAH is founded in arginine metabolism. PaADI catalyzes the first step of the energy-producing arginine degradation pathway found in certain microorganisms, which ultimately leads to ornithine, carbamate, and ATP (12-15). PaAgDI acts on L-arginine-derived agmatine within a biosynthetic pathway that supplies putrescine for polyamine biosynthesis (8). PaDDAH, on the other hand, hydrolyzes $\mathrm{N}^{\omega}$-monomethylated and $\mathrm{N}^{\omega}, \mathrm{N}^{\omega}$-dimethylated L-arginines, which are apparently derived from external sources $(9,10,16)$.

In this paper, we explore the structural changes underlying the divergence of PaADI function within the GMSF. Specifically, the PaADI substrate specificity is defined as are the contributions made by conserved active site residues to substrate recognition and catalysis. Analysis of these results within the framework of structure and substrate specificity

\footnotetext{
${ }^{2}$ In previous publications (for example, see ref 5) regarding this enzyme superfamily, the term "catalytic triad" has been used to confer the participation of the Cys (i.e., Cys406 in PaADI) in nucleophilic catalysis and the His-Glu diad (His278-Glu224 PaADI) in acid-base catalysis. The term "core residues" is used in this paper to reflect the key, essential catalytic residues common to all members of the GMSF. Although Asp280 also plays a key role in PaADI catalysis, its position on the catalytic platform is not conserved among all of the GMSF members (for example, PaDDAH). Therefore, in the context of this restrictive definition it is not considered a core residue.
}

in all three hydrolases offers insight into their origins. Here, we present evidence that suggests that the divergence of the three catalysts occurred at an early stage of GMSF evolution.

\section{MATERIALS AND METHODS}

Materials. Chromatographic materials, buffers, 2-benzyl2-thiopseudourea, L-arginine, L-citrulline, and agmatine were purchased from Sigma, molecular biological materials were from Invitrogen, $\left[1-{ }^{14} \mathrm{C}\right]$-L-arginine (specific activity $=50$ $\mathrm{mCi} / \mathrm{mmol}$ ) was from Moravek Biochemicals, Inc., $N^{\omega_{-}}$ amino-L-arginine was from Alexis Biochemicals, and $N^{\omega_{-}}$ methyl-L-arginine was from Bachem California Inc. $N$-AminoL-citrulline (12) was obtained as a gift from Dr. Bruce King at Wake Forest University.

Arginine Deiminase Gene Cloning and Mutagenesis. PaADI gene (accession number P13981; locus name PA5171) cloning was accomplished using a PCR-based strategy with PfuTurbo DNA polymerase (Stratagene), P. aeruginosa PAO1 genomic DNA (ATCC 47085D), and commercial primers (4). Site-directed mutants were prepared using the pET100/ADIn clone as the template, in conjunction with custom-designed commercial primers, in the PCR reaction. The purified PCR product was digested with BamHI and PstI restriction enzymes and ligated to BamHI- and PstI-digested pET100/ADIn. All gene sequences were verified by DNA sequencing.

Purification of Wild-Type and Mutant Arginine Deiminases. Transformed Escherichia coli BL21 (DE3) cells were grown at $25^{\circ} \mathrm{C}$, with shaking in $3 \times 2 \mathrm{~L}$ of Luria-Bertani medium containing $50 \mu \mathrm{g} / \mathrm{mL}$ ampicillin, to an OD at 600 $\mathrm{nm}=0.6$. Cells were induced with isopropyl $\beta$-D-thiogalactopyranoside $(0.4 \mathrm{mM})$ for $4 \mathrm{~h}$ and harvested by centrifu- 
gation at $4{ }^{\circ} \mathrm{C}(15 \mathrm{~min}$ at $5000 \mathrm{~g})$. The $\sim 18 \mathrm{~g}$ of cell pellet was suspended in $180 \mathrm{~mL}$ of buffer $\left(50 \mathrm{mM} \mathrm{K}{ }^{+}\right.$Hepes containing $1 \mathrm{mM}$ dithiothreitol, $\mathrm{pH} 7.5$ ) at $0{ }^{\circ} \mathrm{C}$ and passed through a French press at 1200 psig. The cell lysate was centrifuged at $48000 \mathrm{~g}$ and $4{ }^{\circ} \mathrm{C}$ for $30 \mathrm{~min}$. The supernatant was loaded onto a $40 \mathrm{~cm} \times 5 \mathrm{~cm}$ DEAE-cellulose column at $4{ }^{\circ} \mathrm{C}$, and the column was eluted with $1 \mathrm{~L}$ of buffer, followed by a $2 \mathrm{~L}$ linear gradient of $0-0.4 \mathrm{M} \mathrm{KCl}$ in buffer. Arginine deiminase-containing fractions (eluted at $0.2 \mathrm{M}$ $\mathrm{KCl})$ were identified by measuring solution absorbance at $280 \mathrm{~nm}$ and arginine deiminase activity (described below). Following SDS-PAGE analysis, selected fractions were combined, adjusted to $10 \%(\mathrm{w} / \mathrm{v})$ in ammonium sulfate, and loaded onto a $18 \mathrm{~cm} \times 3 \mathrm{~cm}$ phenyl-Sepharose column preequilibrated with buffer containing $10 \%$ (w/v) ammonium sulfate. The column was eluted at $4{ }^{\circ} \mathrm{C}$ with $300 \mathrm{~mL}$ of buffer containing $10 \%(\mathrm{w} / \mathrm{v})$ ammonium sulfate followed by a 600 $\mathrm{mL}$ linear gradient of $10 \%(\mathrm{w} / \mathrm{v})$ to $0 \%$ ammonium sulfate in buffer and then with $300 \mathrm{~mL}$ of buffer to elute the arginine deiminase. The combined arginine deiminase-containing fractions were concentrated using an Amicon device (10 kDa disk membrane) followed by a $10 \mathrm{kDa}$ Macrosep centricon (Pall Filtron) device and then dialyzed against buffer. The protein purity was verified by SDS-PAGE analysis. The protein concentration was determined by the Bradford method (17) and by measuring the protein absorbance at 280 $\mathrm{nm}\left(\epsilon=34072 \mathrm{M}^{-1} \mathrm{~cm}^{-1}\right)$. The arginine deiminase mutants were purified and characterized in the same manner as described above for the wild-type deiminase. Where warranted, mutants were chromatographed at $4{ }^{\circ} \mathrm{C}$ on a FPLC Superdex 200 Hi-Load 16/60 column using $25 \mathrm{mM} \mathrm{K}^{+}$Mes/ $0.15 \mathrm{M} \mathrm{KCl} / 0.5 \mathrm{mM}$ DTT (pH 5.6) as eluant at a flow rate of $1 \mathrm{~mL} / \mathrm{min}$ to remove trace contamination by E. coli ADI. The yields of homogeneous ADIs (purity evaluated by SDSPAGE analysis) in units of milligrams of protein per gram wet cell are as follows: PaADI wild type (7), R401A (9), R401L (17), H278A (7), H278V (7), H278N (11), D280A (7), D166A (6), E224A (7), E224D (12), R185A (2), R185L (2), R185K (4), R243A (8), R243L (15), R243K (11), and N160A (3).

ADI N-Terminal Sequence Determination. Wild-type PaADI was chromatographed on a SDS-PAGE gel, transferred to a PVDF membrane (Novex Co.), and subjected to automated $\mathrm{N}$-terminal amino acid sequencing to obtain the sequence Ser-Thr-Glu-Lys-Thr-Lys-Leu-Gly-Val-His.

Steady-State Kinetic Constant Determinations. The $k_{\mathrm{cat}}$ and $K_{\mathrm{m}}$ values were determined from initial velocity data measured as a function of substrate concentration, varied from $0.5 K_{\mathrm{m}}$ to $10 K_{\mathrm{m}}$ in reaction solutions containing $20 \mathrm{mM}$ $\mathrm{MgCl}_{2}$ in $50 \mathrm{mM} \mathrm{K}{ }^{+} \mathrm{Mes}\left(\mathrm{pH} 5.6,25{ }^{\circ} \mathrm{C}\right.$ ). The initial velocities were measured using the colorimetric, fixed-time assay for citrulline described in ref 18 . The reactions of L-arginine were carried out using $0.1 \mu \mathrm{M}$ wild-type PaADI or $10 \mu \mathrm{M}$ mutant PaADI. The reactions of $N^{\omega}$-amino-Larginine and $N^{\omega}$-methyl-L-arginine were carried out using 1 and $10 \mu \mathrm{M}$ wild-type ADI, respectively. Agmatine (5 mM) substrate activity tests were carried out using $10 \mu \mathrm{M}$ wildtype, R185A, or R243A PaADI (5 h incubation). The initial velocity data obtained for active substrates were fitted to the equation $v=V_{\max }[\mathrm{S}] /\left([\mathrm{S}]+K_{\mathrm{m}}\right.$ ) (where $v$ is the initial velocity, $V_{\max }$ the maximum velocity, [S] the substrate concentration, and $K_{\mathrm{m}}$ the Michaelis constant) using the computer program KinetAsyst. The $k_{\text {cat }}$ was calculated from the ratio of $V_{\max }$ and enzyme concentration.

pH Rate Profile Determination. All reactions were carried out at $25^{\circ} \mathrm{C}$ using the following buffers containing $20 \mathrm{mM}$ $\mathrm{MgCl}_{2}: 25 \mathrm{mM} \mathrm{K}^{+}$Mes and $25 \mathrm{mM} \mathrm{K}^{+}$acetate (pH 5.0); 50 $\mathrm{mM} \mathrm{K}^{+}$Mes (pH 5.6); 50 mM Bis-Tris- $\mathrm{HCl}$ (pH 6.6); 50 $\mathrm{mM} \mathrm{K}^{+}$Hepes (pH 7.5); $50 \mathrm{mM} \mathrm{K}^{+}$Taps (pH 8.6). The initial reaction rates were measured using the colorimetric, fixedtime assay (18) for citrulline. The PaADI concentrations used were increased as the reaction solution $\mathrm{pH}$ was increased starting with $0.1 \mu \mathrm{M}$ at $\mathrm{pH} 5$ and ending with $10 \mu \mathrm{M}$ at $\mathrm{pH}$ 8.6.

$\left[{ }^{14}\right.$ C $]$ Arginine-Based Activity Assay for PaADI Mutants. Reaction solutions $(0.5 \mathrm{~mL})$ initially contained $100 \mu \mathrm{M}$ H278A, D166A, or D280A PaADI, $300 \mu \mathrm{M}\left[{ }^{14} \mathrm{C}\right]$ arginine (specific activity $=50 \mathrm{mCi} / \mathrm{mmol}$ diluted 3 -fold with unlabeled arginine), and $20 \mathrm{mM} \mathrm{MgCl} 2$ in $50 \mathrm{mM} \mathrm{K}{ }^{+}$Mes ( $\mathrm{pH} 5.6,25^{\circ} \mathrm{C}$ ). One control reaction solution contained all components except for PaADI, and the second was prepared by adding H278A ADI (final concentration $100 \mu \mathrm{M}$ ) to 300 $\mu \mathrm{M}\left[{ }^{14} \mathrm{C}\right]$ citrulline (generated in situ by incubation of 300 $\mu \mathrm{M}\left[{ }^{14} \mathrm{C}\right]$ arginine with $0.1 \mu \mathrm{M}$ wild-type ADI for $20 \mathrm{~min}$ ) in $20 \mathrm{mM} \mathrm{MgCl} / 20 \mathrm{mM} \mathrm{K}^{+} \mathrm{Mes}\left(\mathrm{pH} 5.6,25^{\circ} \mathrm{C}\right.$ ). At a series of time points, $30 \mu \mathrm{L}$ aliquots of the reaction solution were mixed with $190 \mu \mathrm{L}$ of $0.6 \mathrm{M} \mathrm{HCl}$ and $50 \mu \mathrm{L}$ of carbon tetrachloride using a Vortex mixer and then centrifuged at $14000 \mathrm{rpm}$ for $2 \mathrm{~min}$. The protein pellet was carefully blotted with a piece of Kimwipe paper and then mixed with $4 \mathrm{~mL}$ of scintillation fluid for scintillation counting. The supernatant was chromatographed on a Beckman ultrasphere ODS reversed-phase column $(4.6 \mathrm{~mm} \times 25 \mathrm{~cm}, 5 \mu \mathrm{m})$ to separate the unreacted $\left[{ }^{14} \mathrm{C}\right]$ arginine from the product $\left[{ }^{14} \mathrm{C}\right]$ citrulline by HPLC (19). The column was eluted with buffer A [25 $\mathrm{mM}$ phosphoric acid, $10 \mathrm{mM}$ hexanesulfonic acid, $0.5 \%$ (v/ v) acetonitrile, $\mathrm{pH}=2.5]$ and buffer $\mathrm{B}$ [ $25 \mathrm{mM}$ phosphoric acid, $10 \mathrm{mM}$ hexanesulfonic acid, 20\% (v/v) acetonitrile, $\mathrm{pH}$ $=2.5$ ] using the following program: $100 \%$ buffer $\mathrm{A}$ for 8 min, $0-100 \%$ buffer B for 2 min, hold at $100 \%$ buffer B for $10 \mathrm{~min}$ and follow with the wash $0-100 \%$ buffer A for $1 \mathrm{~min}$, and finally hold at $100 \%$ buffer A for $9 \mathrm{~min}$. The absorbance of the eluant was monitored at $200 \mathrm{~nm}$. The retention times of L-arginine and L-citrulline were 15-16 and 10-11 min, respectively. The L-arginine- or L-citrullinecontaining fractions were assayed for radioactivity by liquid scintillation counting. The concentrations of the radiolabeled enzyme, L-arginine, and L-citrulline present in the quenched reactions were calculated by dividing the counts per minute (cpm) of the isolated enzyme, L-arginine, or L-citrulline fraction by the total counts per minute and then multiplying by $300 \mu \mathrm{M}$. The background measured for scintillation fluid was $30 \mathrm{cpm}$. The background measured for the enzyme pellet (precipitated at $10 \mathrm{~s}$ ) ranged from 140 to $190 \mathrm{cpm}$. At $52 \mathrm{~h}$ the enzyme pellet counts per minute minus background had reached $700 \mathrm{cpm}$ for His278A, $2200 \mathrm{cpm}$ for D280, and 250 cpm for D166A.

Analysis of Products Formed in the PaADI-Catalyzed Reaction of $N^{\omega}$-Amino-l-arginine. The products formed from the $20 \mathrm{~h}$ reaction of $10 \mathrm{mM} N^{\omega}$-amino-L-arginine with 10 $\mu \mathrm{M}$ PaADI in $20 \mathrm{mM} \mathrm{MgCl}_{2} / 50 \mathrm{mM} \mathrm{K}{ }^{+}$Mes (pH 5.6, 25 ${ }^{\circ} \mathrm{C}$ ) were analyzed by ESI-MS following removal of the enzyme by centrifugal size filtration. L-Citrulline and $N$ amino-L-citrulline were employed as standards. The reaction 
of $1 \mathrm{mM} N^{\omega}$-amino-L-arginine was monitored at various reaction times by HPLC using the protocol described above in conjunction with a UV monitor $(200 \mathrm{~nm})$. The retention times of the standards are 2-2.5 min for $\mathrm{K}^{+} \mathrm{Mes}, 2.5-3 \mathrm{~min}$ for hydrazine, 8-9 min for L-citrulline, and 14-15 min for $N^{\omega}$-amino-L-arginine.

Hydrolysis of 2-Benzyl-2-thiopseudourea. This compound was incubated in $0.6 \mathrm{M} \mathrm{HCl}$ at $25^{\circ} \mathrm{C}$ for 3 days, in $0.6 \mathrm{M}$ $\mathrm{HCl}$ at $100{ }^{\circ} \mathrm{C}$ for $12 \mathrm{~h}$, or in $0.6 \mathrm{M} \mathrm{NaOH}$ at $25^{\circ} \mathrm{C}$ for 5 min prior to NMR (Bruker Avance $500 \mathrm{mHz} ; \mathrm{D}_{2} \mathrm{O}$ solvent; $25^{\circ} \mathrm{C}$ ) analysis. The spectral data measured for the unconsumed reactant at $\mathrm{pH} 0.3$ are as follows: $7.44-7.42(\mathrm{~m}, 5 \mathrm{H})$, 4.36 (s, 2H); ${ }^{13} \mathrm{C}$ NMR 169.7, 133.1, 128.3, 128.10, 127.7, 34.3. The spectral properties measured for the products urea and phenylmethylthiolate at $\mathrm{pH} 13.5$ are as follows: ${ }^{1} \mathrm{H}$ NMR 7.34-7.33 (m, 5H), $3.60(\mathrm{~s}, 2 \mathrm{H}) ;{ }^{13} \mathrm{C}$ NMR 161.9, 146.8, 127.7, 127.0, 124.6, 28.1.

Models of PaADI-N $\mathrm{N}^{\omega}$-Methyl-L-arginine and $\mathrm{PaDDAH}-$ $N^{\omega}-N^{\omega}$-Dimethyl-L-arginine Complexes. In the case of the PaADI-N $N^{\omega}$-methyl-L-arginine complex, the starting geometry was adopted from the C406A-L-arginine $X$-ray structure (20) by replacing the Ala side chain with the Cys side chain and by adding a methyl group to the L-arginine ligand. In the case of the $N^{\omega}, N^{\omega}$-dimethyl-L-arginine-DDAH model, the starting geometry was adopted from the C249S- $L_{-}^{-}$ citrulline $X$-ray structure (PDB code $1 H 70)$ by replacing the $\mathrm{C}=\mathrm{O}$ of the citrulline ligand with the $\mathrm{N}\left(\mathrm{CH}_{3}\right)_{2}$ group. The Michaelis complex was solvated repeatedly with a preequilibrated TIP3P (21) water sphere, which centered at an active site atom with a radius of $25 \AA$. Any water molecules that came within a $2.8 \AA$ radius of a non-hydrogen atom in the protein were deleted. The solvated system was then divided into three near-spherical layers, using the stochastic boundary (SB) protocol (22). The atoms in the innermost reaction zone $(r<22 \AA)$ were governed by Newtonian dynamics. The atoms in the reservoir zone outside the $25 \AA$ radius were fixed at the crystallographic positions. The atoms in the socalled buffer zone were subjected to Langevin dynamics with friction and random forces stemming from the bulk solvent molecules that were not explicitly included in the simulation. The QM/MM minimizations were then carried out using the Charmm program (23). The QM region ( $N$-methyl-L-arginine or $N, N$-dimethyl-L-arginine) was dealt with using the $S C C$ DFTB method (24). Ser249 was minimized in the DDAH$N, N$-dimethyl-L-arginine structure and then manually replaced by cysteine by using InsightII.

\section{RESULTS AND DISCUSSION}

PaADI Characterization. Recombinant wild-type and mutant PaADIs were expressed in E. coli and then purified to homogeneity using a column chromatography based protocol. N-Terminal sequence analysis of the wild-type PaADI subunit (46436 Da theoretical mass) showed that the N-terminal Met had been removed by posttranslational modification. Steady-state kinetic analysis of PaADI catalysis revealed a linear increase in activity with increased solution salt concentration. For example, the initial velocity of the PaADI-catalyzed reaction of $5 \mathrm{mM} \mathrm{L}$-arginine in $50 \mathrm{mM} \mathrm{K}^{+}$Mes ( $\mathrm{pH} 5.6$ ) was increased 8-fold by the addition of 20 $\mathrm{mM} \mathrm{MgCl}_{2}$ and 6-fold by the addition of $60 \mathrm{mM} \mathrm{KCl}$. Consequently, all subsequent kinetic studies were carried out using reactions containing $20 \mathrm{mM} \mathrm{MgCl}$.

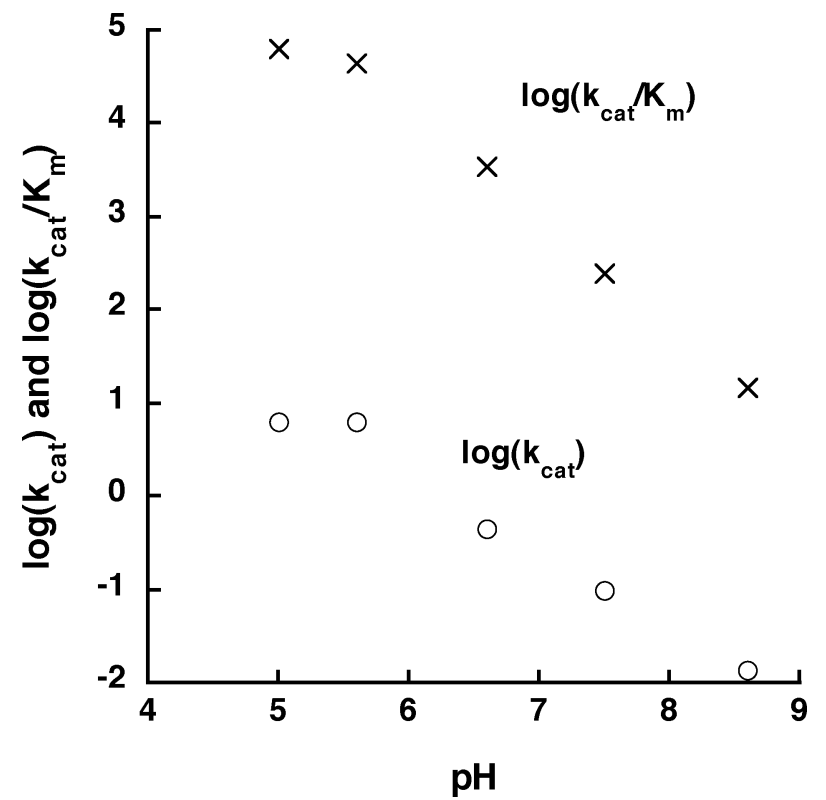

FIGURE 4: $\mathrm{pH}$ rate profiles measured for PaADI-catalyzed hydrolysis of L-arginine to ammonia and citrulline measured at 25 ${ }^{\circ} \mathrm{C}$ using steady-state kinetic techniques (see Materials and Methods section for details).

To determine the optimal $\mathrm{pH}$ for mechanistic studies, the $\mathrm{pH}$ profiles of $k_{\text {cat }}$ and $k_{\text {cat }} / K_{\mathrm{m}}$ for wild-type ADI were measured (Figure 4). These show that the optimal $\mathrm{pH}$ for catalysis is at (or below) pH 5.6 where $k_{\text {cat }}$ is $6 \mathrm{~s}^{-1}$ and the $K_{\mathrm{m}}$ is $140 \mu \mathrm{M}$ (Table 1). PaADI catalytic efficiency decreased with increasing $\mathrm{pH}$ above $\mathrm{pH}$ 5.6. In contrast, the ADIs from Mycoplasma arthritidis and Mycoplasma arginini (MaADIs) function optimally at neutral $\mathrm{pH}(25,26)$. For example, the steady-state kinetic constants measured for the ADI from M. arthritidis at pH 7.2 are $k_{\text {cat }}=29 \mathrm{~s}^{-1}$ and $K_{\mathrm{m}}=4 \mu \mathrm{M}$. In recent (unpublished) $\mathrm{pH}$ rate profile determinations we have observed that the optimal $\mathrm{pH}$ range for catalysis in the Bacillus cereus ADI extends from $\mathrm{pH} 6.0$ to $\mathrm{pH} 7.6$, whereas the optimal pH for $E$. coli ADI is below 6.5 and that for Burholderia mallei is at or below pH 5.6. The reported X-ray structures of PaADI $(4,20)$ and MaADI (27) (ADIs that share $27 \%$ sequence identity) show that the substrate-binding and catalytic residues of these two, relatively divergent orthologues are conserved. Thus, the variation in the $\mathrm{pH}$ optimum for catalysis is intriguing, especially in view of the fact that the intrinsic $\mathrm{p} K_{\mathrm{a}}$ value of solvated His (i.e., $\mathrm{p} K_{\mathrm{a}}=6.1$ ) is such to indicate that the PaADI would initiate a catalytic cycle with its catalytic His278 in the protonated state, whereas MaADI would initiate a catalytic cycle with the His in the unprotonated state. Such a switch in mechanism is hard to imagine, and we must therefore conclude that, despite the difference in optimal $\mathrm{pHs}$, the protonation states of the respective His residues are the same by virtue of $\mathrm{p} K_{\mathrm{a}}$ perturbation by the respective active site environments. As will be discussed below, ADI catalysis involves proton transfer between several residues situated in a highly electrostatic environment. The protonation states of these residues are thus interconnected. Consequently, it is unlikely that the $\mathrm{pH}$ rate profiles, such as those shown in Figure 4, can be used to define the ionization states of the individual residues in the active site during ADI catalysis.

PaADI Substrate Specificity and Divergence of Function. The substrate specificity of the PaDDAH toward L-arginine 
Table 1: Steady-State Kinetic Constants of the P. aeruginosa Guanidinohydrolases Arginine Deiminase (PaADI), Agmatine Deiminase (PaAgDI), and $N^{\omega}, N^{\omega}$-Dimethylarginine Dimethylaminohydrolase (PaDDAH)

\begin{tabular}{clllll}
\hline enzyme & \multicolumn{1}{c}{ substrate } & leaving group & \multicolumn{1}{c}{$k_{\text {cat }}\left(\mathrm{s}^{-1}\right)$} & $K_{\mathrm{m}}(\mathrm{mM})$ & $k_{\text {cat }} / K_{\mathrm{m}}\left(\mathrm{M}^{-1} \mathrm{~s}^{-1}\right)$ \\
\hline $\mathrm{PaADI}^{a}$ & Arg & $\mathrm{NH}_{3}$ & $6.3 \pm 0.1$ & $0.14 \pm 0.01$ & $4.5 \times 10^{4}$ \\
$\mathrm{PaADI}^{a}$ & $N^{\omega}$-methyl-Arg & $\mathrm{CH}_{3} \mathrm{NH}_{2}$ & $1.0( \pm 0.2) \times 10^{-2}$ & $21 \pm 6$ & $4.6 \times 10^{-1}$ \\
$\mathrm{PaADI}^{a}$ & $N^{\omega}$-amino-Arg & $\mathrm{NH}_{2} \mathrm{NH}_{2}$ & $7 \pm 2$ & $50 \pm 20$ & $1.4 \times 10^{2}$ \\
$\mathrm{PaADI}^{a}$ & agmatine & $\mathrm{NH}_{3}$ & no activity & \\
$\mathrm{PaAgDI}^{b}$ & agmatine & $\mathrm{NH}_{3}$ & 4.2 & 0.6 & $7 \times 10^{3}$ \\
$\mathrm{PaAgDI}^{b}$ & Arg & $\mathrm{NH}_{3}$ & no activity & \\
$\mathrm{PaDDAH}^{c}$ & $\mathrm{Arg}$ & $\mathrm{NH}_{3}$ & $1 \times 10^{-3}$ & & 0.94 \\
$\mathrm{PaDDAH}^{c}$ & $N^{\omega}$-methyl-Arg & $\mathrm{CH}_{3} \mathrm{NH}_{2}$ & $3.1 \times 10^{-1}$ & 0.67 & 1.8 \\
$\mathrm{PaDDAH}^{c}$ & $N^{\omega}$-amino-Arg & $\mathrm{NH}_{2} \mathrm{NH}_{2}$ & $1.2 \times 10^{-1}$ & 1.1 & $4.6 \times 10^{2}$ \\
PaDDAH $^{c}$ & $N^{\omega}$-dimethyl-Arg & $\left(\mathrm{CH}_{3}\right)_{2} \mathrm{NH}$ & $5.6 \times 10^{-1}$ & 0.31 & $1.1 \times 10^{2}$ \\
\hline
\end{tabular}

${ }^{a}$ The kinetic constants were measured in this work for reactions carried out in $50 \mathrm{mM} \mathrm{K}^{+} \mathrm{Mes}$ containing $20 \mathrm{mM} \mathrm{MgCl}_{2}\left(\mathrm{pH} 5.6\right.$ and $\left.25{ }^{\circ} \mathrm{C}\right)$. ${ }^{b}$ The kinetic constants were reported in ref 8 for reactions carried out at $45^{\circ} \mathrm{C}$ in Tris- $\mathrm{HCl}$ buffer $(\mathrm{pH} 8.0) .{ }^{c}$ The kinetic constants were reported in ref 10 for reactions carried out at $25^{\circ} \mathrm{C}$ in $100 \mathrm{mM}$ phosphate buffer (pH 6.2). ${ }^{d}$ Reaction solutions initially containing $5 \mathrm{mM}$ reactant and 10 $\mu \mathrm{M}$ wild-type PaADI in $50 \mathrm{mM} \mathrm{K}{ }^{+}$Mes containing $20 \mathrm{mM} \mathrm{MgCl}_{2}\left(\mathrm{pH} 5.6\right.$ and $\left.25^{\circ} \mathrm{C}\right)$ were incubated for $5 \mathrm{~h}$ before assaying for citrulline.

and a variety of $\mathrm{N}^{\omega}$-substituted arginine analogues has been studied by Fast and co-workers (10), who recently reported the steady-state kinetic constants listed in Table 1. The order of reactivity is L-arginine $\left(k_{\mathrm{cat}} / K_{\mathrm{m}}=1.8 \mathrm{M}^{-1} \mathrm{~s}^{-1}\right), N^{\omega}$-aminoL-arginine $\left(k_{\mathrm{cat}} / K_{\mathrm{m}}=1.1 \times 10^{2} \mathrm{M}^{-1} \mathrm{~s}^{-1}\right), N^{\omega}$-methyl-Larginine $\left(k_{\text {cat }} / K_{\mathrm{m}}=4.6 \times 10^{2} \mathrm{M}^{-1} \mathrm{~s}^{-1}\right)$, and $N^{\omega}, N^{\omega}$-dimethylL-arginine $\left(k_{\text {cat }} / K_{\mathrm{m}}=1.8 \times 10^{3} \mathrm{M}^{-1} \mathrm{~s}^{-1}\right)$. The common product formed in these reactions is citrulline. The leaving groups displaced by the Cys nucleophile are the ammonia, hydrazine, methylamine, and dimethylamine, respectively. Thus, leaving group size and/or polarity appear(s) to be important determinants of reactivity. It is clear from this activity profile that the PaDDAH active site is tailored to discriminate between L-arginine and the intended substrate $N^{\omega}, N^{\omega}$-dimethyl-L-arginine, which would be essential for the conservation of cellular L-arginine pools.

In the present study, the steady-state kinetic constants of L-arginine, $N^{\omega}$-amino-L-arginine, and $N^{\omega}$-methyl-L-arginine in reaction with PaADI were measured and are reported in Table 1. The order of increasing reactivity is $N^{\omega}$-methyl-Larginine $\left(k_{\mathrm{cat}} / K_{\mathrm{m}}=4.6 \times 10^{-1} \mathrm{M}^{-1} \mathrm{~s}^{-1}\right), N^{\omega}$-amino-L-arginine $\left(k_{\text {cat }} / K_{\mathrm{m}}=1.4 \times 10^{2} \mathrm{M}^{-1} \mathrm{~s}^{-1}\right)$, and L-arginine $\left(k_{\text {cat }} / K_{\mathrm{m}}=4.5\right.$ $\left.\times 10^{4} \mathrm{M}^{-1} \mathrm{~s}^{-1}\right)$. Because the substrate activity of the $N^{\omega_{-}}$ amino-L-arginine is distinguished from that of L-arginine not by $k_{\text {cat }}$, but rather by $K_{\mathrm{m}}(50$ vs $0.14 \mathrm{mM})$, it became necessary to demonstrate that the $N^{\omega}$-amino-L-arginine is in fact hydrolyzed. Accordingly, the time course for product formation in a reaction solution initially containing $10 \mathrm{mM}$ $N^{\omega}$-amino-L-arginine and $3 \mu \mathrm{M}$ PaADI is shown in Figure 1 of Supporting Information. The $N^{\omega}$-amino-L-arginine was quantitatively converted at an initial turnover rate (i.e., based on $0-20 \%$ conversion) of $2 \mathrm{~s}^{-1}$, which is consistent with the $k_{\text {cat }}=7 \pm 2 \mathrm{~s}^{-1}$ determined by the steady-state kinetic method (Table 1). This result demonstrates that the steadystate kinetic constants measured for $N^{\omega}$-amino-L-arginine are based on the hydrolysis of it, rather than on the hydrolysis of contaminating L-arginine (listed by the product manufacturer as a $0.6 \%$ contaminant).

A second issue that required clarification concerns the identity of the leaving group in the PaADI-catalyzed hydrolysis of the $N^{\omega}$-amino-L-arginine. The colorimetric-based assay used for the kinetic studies does not distinguish between the citrulline formed by displacement of the $\mathrm{NH}_{2}$ $\mathrm{NH}_{2}$ group vs $N^{\omega}$-aminocitrulline formed by displacement of the $\mathrm{NH}_{3}$ group. The HPLC-based analysis of the product mixture, using citrulline and hydrazine as chromatographic standards, evidenced the hydrazine-forming pathway (see Figure 2 of Supporting Information). Product identity was confirmed by ES-MS analysis of the product mixture, which showed a spectral peak at $176 \mathrm{Da}$ corresponding to citrulline (see Figure 3 of Supporting Information). The absence of a peak corresponding to $191 \mathrm{Da}$, observed for the $N^{\omega}$-aminoL-citrulline standard, ruled out the $\mathrm{NH}_{2}$ group cleavage pathway. Accordingly, the PaADI-catalyzed hydrolysis of $N^{\omega}$-amino-L-arginine occurs with the displacement of hydrazine rather than ammonia. By analogy, we assume that the hydrolysis of $N^{\omega}$-methyl-L-arginine occurs with loss of methylamine.

Whereas PaADI is most active with L-arginine, PaDDAH is most active with the $N^{\omega}$-methylated L-arginine adducts. Comparison of the PaADI and PaDDAH active sites provides insight into the structural basis for this difference in substrate preference. Figure 5A shows the PaADI active site region that encapsulates the L-arginine guanidino group as defined by the X-ray structure of the C406A PaADI-L-arginine complex (20). The $N^{\omega}$-methyl-L-arginine ligand shown in Figure 5A was modeled in place of the L-arginine ligand, and the Ala406 side chain was replaced with the native Cys side chain as described in the Materials and Methods section. Although the PaADI active site has room to accommodate the $N^{\omega}$-methylamino group, the electrostatic field that emanates from the charged carboxylate group of the nearby Asp280 (whose location on the catalytic scaffold is illustrated in Figure 1B) is not balanced through $\mathrm{H}$-bond interaction because of steric interference from the $N^{\omega}$-methyl group. In the L-arginine complex, the Asp280 carboxylate engages in hydrogen bond interaction with both guanidino group $\mathrm{NH}_{2}$ substituents. The faster turnover of the PaADI bound $N^{\omega_{-}}$ amino-L-arginine ligand vs bound $N^{\omega}$-methyl-L-arginine ligand might reflect the ability for the $\mathrm{N}^{\omega}-\mathrm{NH}_{2}$ to engage in hydrogen bond interaction with the Asp280 in place of the $\mathrm{N}^{\omega}-\mathrm{H}$. The PaAgDI active site (Figure 6) places Asp226 in the same position occupied by Asp280 in PaAgDI. Thus, we might anticipate that $\mathrm{N}^{\omega}$-substituted agmatine derivatives are not good substrates for this enzyme for the same reason that the corresponding L-arginine derivatives are not good substrates for PaADI. PaAgDI substrate specificity is indeed stringent; however, these compounds were not among those that have been tested as substrates (8), and therefore this point remains to be verified. 

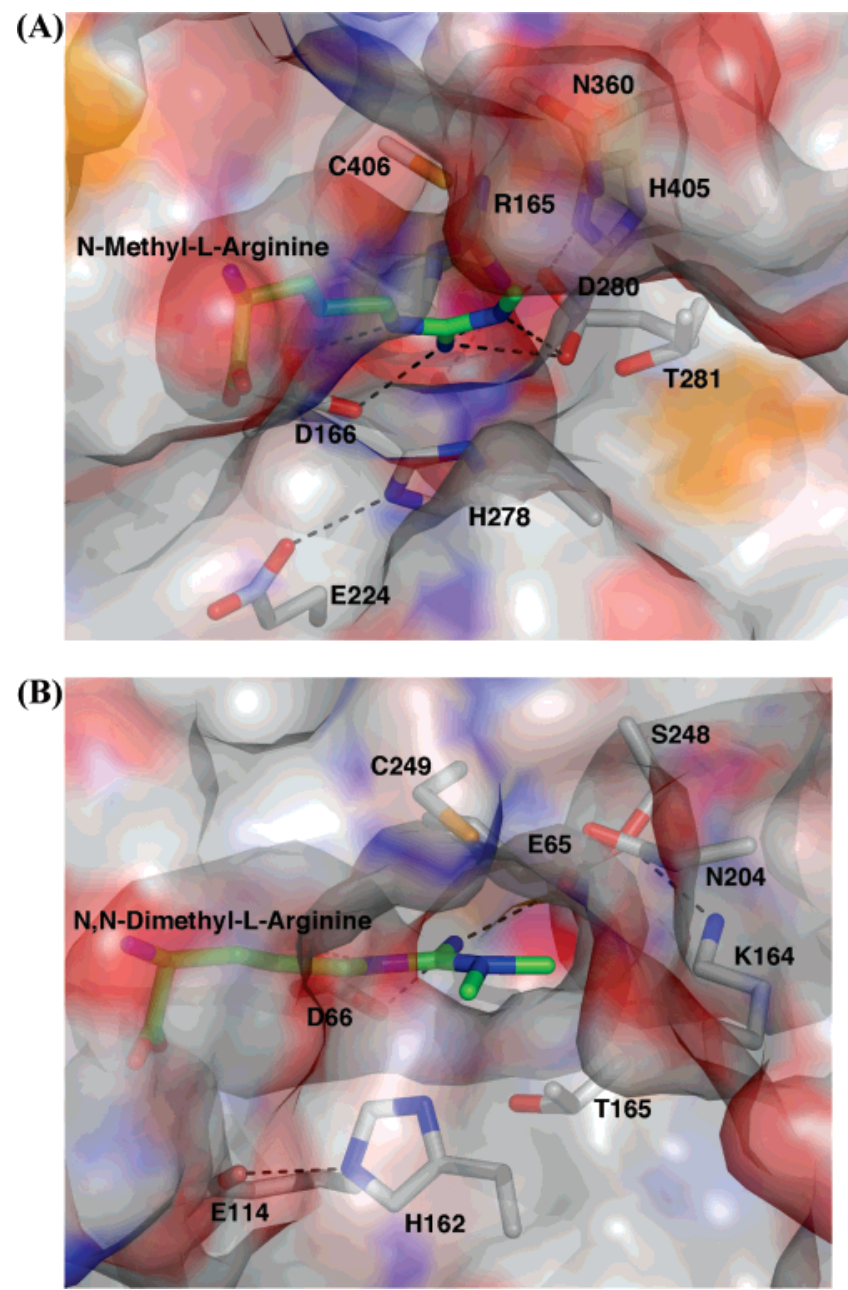

FIGURE 5: Illustration of the guanidino group binding sites in PaADI and PaDDAH. The $N^{\omega}$-methyl-L-arginine ligand was docked into the substrate-binding site observed in the PaADI C401A-L-arginine structure (20) using the methodology described in the Materials and Methods section. The $N^{\omega}, N^{\omega}$-dimethyl-L-arginine ligand was placed in the substrate-binding site observed in the PaDDAHcitrulline structure (5) as described in the Materials and Methods section. The atom colors are as follows: oxygen (red), nitrogen (blue), sulfur (orange), and carbon (gray). Ligand carbon atoms are in green. Hydrogen bond interactions are displayed by using black dashed lines.

Despite the conservation of core catalytic residues, the PaDDAH active site differs quite a bit from the active sites of PaADI and the PaAgDI. The binding pocket of PaDDAH complements the dimethylamine substituent of the $N^{\omega}, N^{\omega_{-}}$ dimethyl-L-arginine substrate. The charged Asp280 residue of the corresponding region in PaADI is absent (Figure 6). In its place is Lys164 (see Figure 1B). The PaDDAH Lys164 side chain is oriented to form an ion pair with Glu65, which, as illustrated in Figure 1B, corresponds to Arg 165 in PaADI. This orientation creates additional room near the substrate's leaving group, and importantly, it allows the hydrocarbon unit of Lys146, together with the carbon unit of Thr165, to form a hydrophobic surface that interfaces with the $N^{\omega_{-}}$ methyl groups. The dimethylamine substituent locks the $N^{\omega}, N^{\omega}$-dimethyl-L-arginine substrate into the PaDDAH active site, in position for catalysis. The smaller $\mathrm{NH}_{2}$ substituent of the L-arginine substrate would not be within contact distance of the surrounding active site residues, and for this reason the L-arginine might bind in a less favorable orientation for catalysis. Thus, it is apparent why L-arginine is not

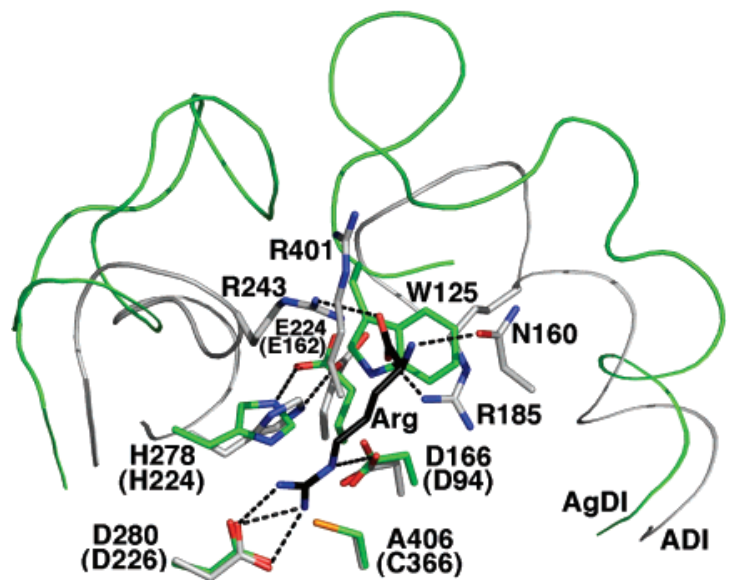

FIGURE 6: Overlay of the PaADI C406A-L-arginine structure (20) and the unliganded A. thaliana AgDI structure (6) (PDB code 1VKP). Atoms are colored as follows: oxygen (red), nitrogen (blue), sulfur (orange), carbon in ADI (gray), and carbon in AgDI (green). Backbone colors are as follows: ADI (gray) and AgDI (green).

a good substrate for the PaDAAH and why substrate activity is increased by $\mathrm{N}^{\omega}$-methylation (Table 1 ).

As mentioned previously, the PaADI Asp280 carboxylate group interacts with both guanidino group $\mathrm{NH}_{2}$ substituents of the L-arginine substrate. The PaDDAH Glu65 carboxylate group reaches the positively charged $\mathrm{NH}_{2}$ substituent of the $N^{\omega}, N^{\omega}$-dimethyl-L-arginine ligand for favorable interaction, yet it does so from a different peptide segment of the GMSF catalytic scaffold (Figure 1B). This scaffold "retooling" coupled with the compensatory changes made in connecting, secondary residues (for example, PaADI His 405 that interacts with Asp280 is replaced in PaDDAH with Ser248; see Figure 6) indicates that the structural changes underlying the substrate specificity differences in PaDDAH and PaADI occurred on a larger scale than that expected for the relatively small change in the substrate structure. Indeed, nature's "redesign" contrasts the strategic amino acid targeting approach that a protein engineer might take in expanding or retracting the binding site to accommodate the desired substrate.

To compare the elements of substrate recognition in PaADI to those of PaAgDI, we draw on the published PaAgDI substrate specificity screen $(8)$ and the unpublished structure report of the AgDI from A. Thaliana (PDB code 1VKP (6); accession number Q9LEZ0) (AtAgDI). The PaAgDI and AtAgDI share 54\% sequence identity, including the residues that are mentioned here. Whereas PaAgDI catalyzes deimination of L-agmatine but not L-arginine (8), PaADI catalyzes deimination of L-arginine but not agmatine (Table 1). In Figure 6, the active sites of PaADI and AtAgDI are superimposed to illustrate the conservation of the core catalytic residues (Cys406, His278, and Asp166 in PaADI and Cys366, His224, and Asp94 in AtAgDI), the fourth reaction center residue (Asp280 in PaADI, Asp226 in AtAgDI), and the divergence of the residues surrounding the $\mathrm{C}^{\alpha}$ substituents of the PaADI-L-arginine ligand. In PaADI (and in $\mathrm{PaDDAH}$, Figure 1B), the substrate $\mathrm{C}^{\alpha}-\mathrm{COO}^{-}$group forms salt bridges with two Arg residues (Arg185/Arg243 PaADI and Arg85/Arg132 PaDDAH). AtAgDI, whose substrate lacks the $\mathrm{C}^{\alpha}-\mathrm{COO}^{-}$group, does not position $\mathrm{Arg}$ residues in this region of the active site (see overlay in Figure 
Table 2: Steady-State Kinetic Constants Measured for Wild-Type and Mutant PaADI Catalyzed Hydrolysis of L-Arginine to Ammonia and Citrulline in $50 \mathrm{mM} \mathrm{K}{ }^{+} \mathrm{Mes} / 20 \mathrm{mM} \mathrm{MgCl} 2\left(\mathrm{pH} \mathrm{5.6,25}{ }^{\circ} \mathrm{C}\right)$

\begin{tabular}{|c|c|c|c|}
\hline enzyme & $k_{\mathrm{cat}}\left(\mathrm{s}^{-1}\right)$ & $K_{\mathrm{m}}(\mathrm{mM})$ & $\begin{array}{c}k_{\mathrm{cat}} / K_{\mathrm{m}} \\
\left(\mathrm{M}^{-1} \mathrm{~s}^{-1}\right)\end{array}$ \\
\hline wild type & $6.3 \pm 0.2$ & $0.14 \pm 0.02$ & $4.5 \times 10^{4}$ \\
\hline $\mathrm{C} 406 \mathrm{~A}$ & & inactive & \\
\hline C406S & & inactive & \\
\hline $\mathrm{H} 278 \mathrm{~A}$ & & inactive & \\
\hline H278V & & inactive & \\
\hline $\mathrm{H} 278 \mathrm{~N}$ & & inactive & \\
\hline D280A & & inactive & \\
\hline D166A & & inactive & \\
\hline E224A & $2.1( \pm 0.2) \times 10^{-3}$ & $1.1 \pm 0.3$ & 1.9 \\
\hline E224D & $3.7( \pm 0.2) \times 10^{-3}$ & $4.2 \pm 0.5$ & 0.9 \\
\hline $\mathrm{R} 185 \mathrm{~A}$ & $8.9( \pm 1.2) \times 10^{-2}$ & $15 \pm 3$ & 5.9 \\
\hline $\mathrm{R} 185 \mathrm{~L}$ & $8.4( \pm 0.5) \times 10^{-3}$ & $4.8 \pm 0.6$ & 1.8 \\
\hline $\mathrm{R} 185 \mathrm{~K}$ & & $\mathrm{ND}^{a}$ & \\
\hline $\mathrm{R} 243 \mathrm{~A}$ & $8.9( \pm 0.2) \times 10^{-4}$ & $2.6 \pm 0.1$ & 0.3 \\
\hline R243L & $9( \pm 1) \times 10^{-3}$ & $38 \pm 8$ & 0.2 \\
\hline R243K & $2.01( \pm 0.02) \times 10^{-3}$ & $6.9 \pm 0.2$ & 0.3 \\
\hline N160A & $2.1( \pm 0.1) \times 10^{-2}$ & $2.7 \pm 0.2$ & 8.0 \\
\hline R401A & $7.2( \pm 0.2) \times 10^{-3}$ & 8.7 & 0.8 \\
\hline $\mathrm{R} 401 \mathrm{~L}$ & $3.6( \pm 0.2) \times 10^{-4}$ & ND & \\
\hline
\end{tabular}

${ }^{a}$ The steady-state kinetics for R185K could not be determined because the enzyme precipitated during the course of the reaction.

6). Instead, the side chain of the AgDI Trp125 fills in the space that might otherwise be occupied by the L-arginine $\mathrm{C}^{\alpha} \mathrm{COO}^{-}$substituent. It is obvious from the structure of the AtAgDI active site that L-arginine cannot be recognized as a substrate. Specifically, there is limited space and the absence of complementary electropositive residues. The agmatine, on the other hand, "fits" within the steric confines of the PaADI active site, yet it is not recognized as a substrate. The absence of the $\mathrm{C}^{\alpha} \mathrm{COO}^{-}$substituent leaves the PaADI Arg185 and Arg243 without a charge counterpart. As part of the mutagenesis study described in the following section, the PaADI Arg185 or Arg243 residues were separately replaced with Ala, and the substrate activity of the two mutant enzymes toward L-arginine and agmatine was measured. Whereas the Ala mutants lost a great deal of catalytic activity toward L-arginine deimination (see Table 2), they did not gain catalytic activity toward agmatine deimination. It remains to be seen whether PaADI substrate specificity could be switched to that of AgADI by replacing both arginine residues simultaneously to alanines or to residues with larger hydrophobic side chains.

Whereas the PaADI and AtAgDI are structurally divergent in the region of the active site that interacts with the $\mathrm{C}^{\alpha} \mathrm{H}\left(\mathrm{NH}_{3}{ }^{+}\right)\left(\mathrm{COO}^{-}\right)$region of the substrate [note from Figure 6 that interactions involving the substrate $\mathrm{C}^{\alpha} \mathrm{NH}_{3}{ }^{+}$group are also different in the two enzymes], the regions that interact with the guanidino group of the substrate are quite similar. In particular, the PaADI Asp280 carboxylate group that interacts with both $\mathrm{NH}_{2}$ substituents of the L-arginine guanidino group is conserved in AtAgDI as Asp226 (and as Asp219 in PaAgDI). Thus, PaADI and PaAgDI use a similar guanidino group binding motif, whereas that used by $\mathrm{PaDDAH}$ is (as previously described) very different. The PaADI and PaDDAH, on the other hand, conserve the L-arginine $\mathrm{C}^{\alpha} \mathrm{H}\left(\mathrm{NH}_{3}{ }^{+}\right)\left(\mathrm{COO}^{-}\right)$moiety binding motif that has diverged beyond recognition in PaAgDI.

The structural divergence that is observed between PaADI, $\mathrm{PaDDAH}$, and PaAgDI underlies the clear boundaries that exist in their substrate specificities. Despite their unique substrate specificity, the three hydrolases retain the "Cys, His, Asp" core residues. In the section that follows, the contributions made by these and other PaADI active site residues in catalysis of L-arginine deimination are examined.

Functional Roles of PaADI Active Site Residues. Prior to the present studies, the PaADI active site structure had been defined by X-ray structure determination of the apoenzyme (4) to reveal an extensive network of electrostatic interactions. The side chain of Arg401, located at the active site entrance, filled the substrate-binding site (4). The recent structure determination of the C406A PaADI-L-arginine complex (20) shows that the Arg401 side chain is displaced by the substrate to a position near the active site entrance that allows its hydrocarbon chain to assist shielding the catalytic site from solvent (Figure 6). Curiously, Arg401 is replaced with Met in MaADI, but when Arg401 is replaced by site-directed mutagenesis, the resulting R401M PaADI mutant protein was found to be insoluble. The R401A and R401L PaADI mutants are, however, soluble, nativelike proteins. The steady-state kinetic constants measured for these two mutants (Table 2) reflect significantly reduced (>10000-fold) catalytic efficiency. Thus, Arg401 plays an important functional role in PaADI catalysis, and by analogy we might anticipate that Met393 also plays such a role in MaADI catalysis. The structures of PaADI and MaADI (27) have thus diverged to accommodate different active site gating residues.

$\mathrm{X}$-ray crystallographic structure determination of the C406A PaADI-L-arginine complex (20) identified Arg 185 and $\mathrm{Arg} 243$ as the major substrate $\mathrm{C}^{\alpha}-\mathrm{COO}^{-}$binding residues (as described in the previous section) (Figure 6). These residues were separately replaced with Lys, Leu, or Ala by site-directed mutagenesis. The steady-state kinetic properties of the mutants listed in Table 2 reflect 4-5 orders of magnitude reduction in catalytic efficiency. As mentioned in the previous section, R185A and R243A PaADI did not catalyze the hydrolysis of agmatine at a detectable rate. The L-arginine $\mathrm{C}^{\alpha} \mathrm{NH}_{3}{ }^{+}$substituent engages in hydrogen bond interaction with the backbone amide $\mathrm{C}=\mathrm{O}$ of Leu41 and Gly400 and the side chain of Asn160 (Figure 6). Surprisingly, the catalytic efficiency of the N160A mutant is reduced 5000fold.

It is clear from these mutagenesis data that catalysis in PaADI is exquisitely sensitive to changes made in the constellation of active site residues. The Arg185, Arg243, and Asn160 residues bind the "tail end" of the substrate and are secondary to the actual catalytic residues, yet their substitution greatly diminishes the rate of deimination of the bound substrate. The $K_{\mathrm{m}}$ values increase by $1-2$ orders of magnitude, but the reduction in $k_{\text {cat }}$ values is more even extreme at 2-4 orders of magnitude (Table 2).

The GMSF core catalytic residues of PaADI are Cys406, His278, and Asp166. In PaADI, Asp280 joins the core residues to encase the substrate guanidino group, which together make up the reaction center (see Figure 1B). Asp280 and Asp166 are positioned for ion pair formation with the guanidino group, which is flanked on either side by the Cys406 thiolate and the His278 imidazolium ring. ${ }^{3}$ The

\footnotetext{
${ }^{3}$ The ionization states of the His 278 and the Cys406 in the enzymesubstrate complex are assumed and not yet proven.
} 
$\mathrm{N}(1) \mathrm{H}$ of His278 engages in hydrogen bond formation with the carboxylate group of Glu224 (shown in Figure 5A). The Glu224-His278 pair has a counterpart in PaDDAH (5) (see Figure 5B) and in PaAgDI (see AtAgDI in Figure 6) (6). In Figure 3, a working model of the catalytic mechanism shared by these enzymes is depicted. According to this model, Cys406 functions in nucleophilic catalysis, a role for which there is considerable supporting evidence $(1,4,5,10,11$, $20,27)$. On the basis of its position in the catalytic site it is suggested that His278 serves in general acid catalysis (to protonate the displaced $\mathrm{NH}_{2}$ group) and in general base catalysis (to deprotonate the attacking water molecule). Asp166, on the other hand, is positioned for interaction with the two guanidino group NHs retained in the citrulline product. Asp280 is positioned for binding both external NHs of the substrate guanidino group, as well as the water nucleophile (Figures $1 \mathrm{~B}$ and $5 \mathrm{~A}$ ).

To evaluate the rate contributions made by the abovementioned PaADI active site residues, the residues were individually mutated, and the steady-state kinetic constants of the mutant enzymes were measured (Table 2). The $k_{\text {cat }} /$ $K_{\mathrm{m}}$ values measured for the E224A and E224D PaADI mutants are 4 orders of magnitude smaller than that of wildtype PaADI. This rate contribution is consistent with the proposed role of Glu224 in both orienting and modulating the acidity/basicity of His278. The PaADI Glu224 counterpart in PaAgADI is Glu156, in AtAgDI Glu162 (Figure 6), and in PaDDAH Glu114 (Figure 5B). On the basis of the present findings, it is likely that these Glu residues also make significant contributions to catalysis in their respective enzymes.

The C406A, C406S, H278A, H278V, H278N, D280A, and D166A PaADI were found, based on the detection limit of the citrulline fixed-time colorimetric-based assay (sets the maximum value for $k_{\text {cat }}$ to less than $1 \times 10^{-4} \mathrm{~s}^{-1}$ ), to be catalytically inactive. Because these mutants were used in cocrystallization experiments with L-arginine, a more sensitive radioisotope-based activity assay was employed to test catalytic activity. Accordingly, reaction solutions initially containing $100 \mu \mathrm{M}$ PaADI mutant and $300 \mu \mathrm{M}\left[{ }^{14} \mathrm{C}(1)\right]-\mathrm{L}-$ arginine in $50 \mathrm{mM} \mathrm{K}{ }^{+} \mathrm{Mes} / 20 \mathrm{mM} \mathrm{MgCl}{ }_{2}$ were incubated at $25^{\circ} \mathrm{C}$ for $50 \mathrm{~h}$. Aliquots were removed to assay covalently radiolabeled enzyme, citrulline, and unconsumed L-arginine. Because of the long incubations times employed, care was taken to remove traces of monomeric $E$. coli ADI from the tetrameric PaADI mutant proteins (isolated from $E$. coli cells) using FPLC gel size filtration chromatography. The level of conversion of L-arginine to citrulline in the ultrapure PaADI mutant was found to be insignificant. The H278A and D280A PaADI mutants showed a significant level of covalent enzyme adduct formation within a $50 \mathrm{~h}$ incubation period (Figure 7). In contrast, neither C406A PaADI (not shown) nor D166A PaADI (Figure 7) formed a significant level of covalent adduct. Consistent with the solution studies, crystals formed in mixtures of these PaADI mutants with L-arginine have provided structures (20) of apo D166A PaADI and C406A PaADI-L-arginine as well as the H278A and D280A PaADI Cys406-S-1-(iminomethyl)-L-ornithine complexes [i.e., the thioalkyluronium intermediate pictured in Figure 3 and previously identified as a transient intermediate of wildtype PaADI catalysis (11)].
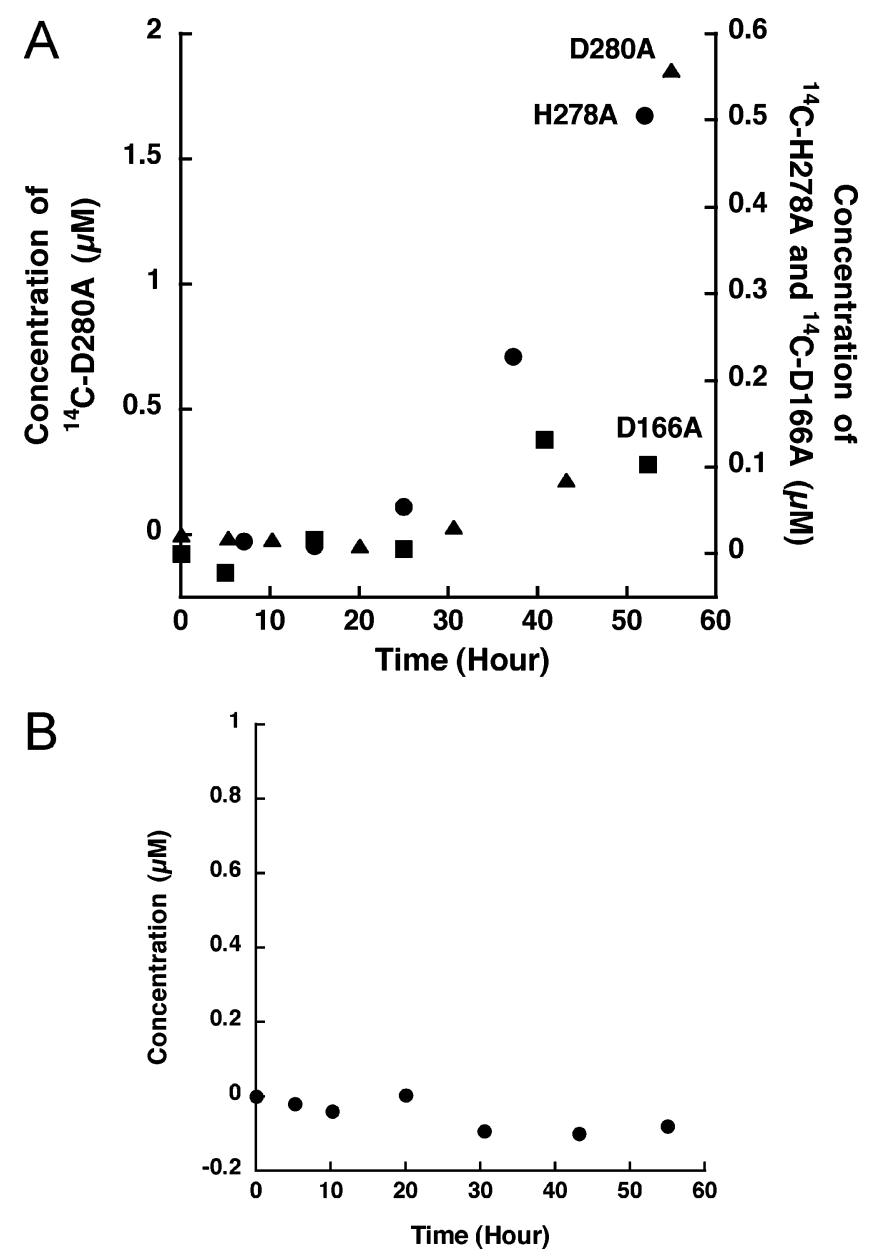

Figure 7: (A) Time courses for the formation of ${ }^{14} \mathrm{C}$-labeled enzyme in reactions of $100 \mu \mathrm{M} \mathrm{H} 278 \mathrm{~A}, \mathrm{D} 280 \mathrm{~A}$, or D166A PaADI with $300 \mu \mathrm{M}\left[1-{ }^{14} \mathrm{C}\right]$-L-arginine in $50 \mathrm{mM} \mathrm{K}+\mathrm{Mes} / 20 \mathrm{mM} \mathrm{MgCl} 2$ (pH 5.6) at $25^{\circ} \mathrm{C}$. Key: circles, H278A; triangles, D280A; squares, D166A. (B) Time course of ${ }^{14} \mathrm{C}$-labeled enzyme in reaction of 100 $\mu \mathrm{M} \mathrm{H} 278 \mathrm{~A} \mathrm{PaADI}$ and $300 \mu \mathrm{M}\left[1-{ }^{14} \mathrm{C}\right]-\mathrm{L}$-citrulline under the same condition as described in (A). The $300 \mu \mathrm{M}\left[1-{ }^{14} \mathrm{C}\right]$-L-citrulline was generated by treating $300 \mu \mathrm{M}\left[1-{ }^{14} \mathrm{C}\right]$-L-arginine with $0.1 \mu \mathrm{M}$ wildtype PaADI for $20 \mathrm{~min}$. See the Materials and Methods section for details.

The curved appearance of the time courses for covalent enzyme formation in H278A and D280A PaADI (Figure 7) is suggestive of a delayed onset of the covalent modification, perhaps deriving from a slow conformational change. However, this lag might be an artifact of the assay, which relies on the detection of low-level radioactivity over background radioactivity (see Materials and Methods section). The amount of covalent enzyme adduct that accumulates within $50 \mathrm{~h}$ is indeed small: $\sim 0.5 \mu \mathrm{M}$ for $\mathrm{H} 278 \mathrm{~A}$ PaADI and $\sim 2 \mu \mathrm{M}$ for D280A PaADI. Crystallization of the protein complexes reported in ref 20 , however, took place over a much longer time frame (i.e., weeks), which might account for the slow, selective growth of crystals of the intermediate complex.

Finally, we confirmed that the intermediate is formed by the forward reaction of L-arginine rather than the backward reaction. This was shown by the incubation of the His278A PaADI with $\left[{ }^{14} \mathrm{C}\right]$ citrulline, which did not lead to covalent enzyme adduct formation (Figure 7). ${ }^{4}$

Implications of Base-Catalyzed Hydrolysis in a Chemical Model of the PaADI Cys406-S-alkyluronium Intermediate. 
The compound 2-benzyl-2-thiopseudourea was prepared to serve as a model to test solution-mediated acid and base catalysis of hydrolytic $\mathrm{C}-\mathrm{S}$ bond cleavage. The 2-benzyl2-thiopseudourea was found to be stable in dilute aqueous acid $\left(0.6 \mathrm{M} \mathrm{HCl}\right.$; no reaction after $12 \mathrm{~h}$ at $\left.100{ }^{\circ} \mathrm{C}\right)$ but was rapidly hydrolyzed in dilute aqueous base $(0.6 \mathrm{M} \mathrm{NaOH}$, reaction complete within $5 \mathrm{~min}$ at $25^{\circ} \mathrm{C}$ ). The $S$-benzylthiouronium ion, which predominates in the acidic solution, was not noticeably reactive with the water nucleophile. In contrast, the $S$-benzylthiourea, which predominates in the aqueous base, was found to be highly reactive with the hydroxide nucleophile.

These results suggest that during turnover PaADI must activate a water molecule for attack at the $\mathrm{C}^{\xi}$ of the Cys406$S$-alkyluronium ion intermediate. His278 and Asp280 are positioned for this role (Figure 1B). Wild-type (11), H278A, and D280A PaADI accumulate the Cys-S-alkyluronium intermediate, but as we have shown here the H278A and D280A PaADI mutants do so quite slowly (Figure 7). This indicates that His278 and Asp280 are required both for the formation and the hydrolysis of the intermediate. Moreover, the observation that these mutants fail to produce citrulline suggests that both His278 and Asp280 are also used in the activation of the hydrolytic water molecule.

\section{SUMMARY AND CONCLUSIONS}

The catalytic scaffold of the enzymes of the guanidinotransferring enzyme superfamily (1) has diversified to catalyze guanidino group transfer to a variety of acceptors and to recognize altered forms of L-arginine as donor, while retaining the Cys, His, Asp catalytic core. In this study, we have focused on the diversification of the catalytic sites of three different hydrolases of the human pathogen $P$. aeruginosa. The PaADI and PaDDAH station two Arg residues to bind the $\mathrm{C}^{\alpha}-\mathrm{COO}^{-}$group whereas the PaAgDI, which binds a substrate that does not possess the $\mathrm{C}^{\alpha}-\mathrm{COO}^{-}$group, lacks these residues. The catalytic scaffolds of PaADI and PaAgDI station a second Asp residue to bind the two external guanidino $\mathrm{NH}_{2}$ groups of the substrate. To accommodate its ${ }^{\omega} \mathrm{N}$-dimethylated substrate, PaDDAH uses a different station on the catalytic scaffold to position a Glu that can bind the guanidino $\mathrm{NH}_{2}$ group. Nevertheless, all three enzymes conserve the Cys nucleophile, the His residue that is positioned to function in acid-base catalysis, and the Asp residue that binds the substrate guanidino group, and these residues make up the catalytic core.

The PaADI active site is not resilient to amino acid substitutions. Substitutions of substrate-binding residues cause dramatic reductions in turnover rate, suggesting that catalysis rests on electrostatic interactions which determine the protonation states and orientations of the residues that are positioned to function in nucleophilic and general acidbase catalysis. From a protein engineering perspective, the $\mathrm{PaADI}$ active site might be modified to accept agmatine or

\footnotetext{
${ }^{4}$ In contrast, Arnold and co-workers have reported the structures of both the Cys-S-alkyl tetrahedral intermediate and the Cys-alkylthiouronium intermediate formed by crystallization of wild-type MaADI in the presence of L-arginine (27) (see Figure 3). This incubation mixture consists mainly of L-citrulline and, thus, leaves one to conclude that the back-reaction provides the accumulation of the respective covalent enzyme intermediates observed in the two distinct crystal forms (27).
}

$N^{\omega}, N^{\omega}$-dimethyl-L-arginine as substrate in place of L-arginine, using a few, strategic amino acid substitutions. In contrast, the three separate and nonoverlapping biochemical functions of PaADI, PaDDAH, and PaAgDI derive from catalytic scaffolds that have undergone a great deal of retooling. The occurrence of all three hydrolases in $P$. aeruginosa is suggestive of gene recruitment to form secondary metabolic pathways that facilitate environmental adaptation. The ADI functions in a pathway used by primitive eukaryotes (Giardia) and primitive bacteria (Mycoplasma) as well as a wide range of eubacteria to convert excess L-arginine to chemical energy (ATP). The AgDI occurs in primitive bacteria as well as in a variety of eubacteria and in plants to convert L-arginine to putrescine for polyamine biosynthesis. The DDAH functions in eukaryotes to hydrolyze the $N^{\omega}, N^{\omega_{-}}$ dimethyl-L-arginine released from Arg-methylated proteins, a biochemical function that might be tied to NO synthase regulation (5). The occurrence of DDAH in bacteria is limited in scope (28). The sequence identity between eukaryotic and bacterial ADI (30\%) is significantly higher than the sequence identities existing between the PaDDAH and the sequences of PaADI or PaAgDI $(\sim 15 \%)$. Moreover, the sequence identity between PaAgDI and AtAgDI is 54\%, while that between PaAgDI and AgDI in other bacteria outside of the Pseudomonas genera is lower (viz., 50-30\% sequence identity). These observations suggest that the PaDDAH and PaADI genes might have been recruited from eukaryotes; however, further analysis will be required to evaluate this possibility.

\section{ACKNOWLEDGMENT}

The authors thank Dr. Bruce King of Wake Forrest University for providing a sample of $\mathrm{N}$-amino-L-citrulline.

\section{SUPPORTING INFORMATION AVAILABLE}

Three figures depicting the time course of the formation of L-citrulline in the reaction of $10 \mathrm{mM} N^{\omega}$-amino-L-arginine with $3 \mu \mathrm{M}$ arginine deiminase, the HPLC analysis of the reaction of $10 \mathrm{mM} N^{\omega}$-amino-L-arginine with $1 \mu \mathrm{M}$ arginine deiminase, and the ESI-MS analysis of the reaction of 10 $\mathrm{mM} N^{\omega}$-amino-L-arginine with $10 \mu \mathrm{M}$ arginine deiminase. This material is available free of charge via the Internet at http://pubs.acs.org.

\section{REFERENCES}

1. Shirai, H., Blundell, T. L., and Mizuguchi, K. (2001) A novel superfamily of enzymes that catalyze the modification of guanidino groups, Trends Biochem. Sci. 26, 465-468.

2. Tocilj, A., Schrag, J. D., Li, Y., Schneider, B. L., Reitzer, L., Matte, A., and Cygler, M. (2005) Crystal structure of $N$-succinylarginine dihydrolase AstB, bound to substrate and product, an enzyme from the arginine catabolic pathway of Escherichia coli, J. Biol. Chem. $280,15800-15808$.

3. Itoh, Y. (1997) Cloning and characterization of the aru genes encoding enzymes of the catabolic arginine succinyltransferase pathway in Pseudomonas aeruginosa, J. Bacteriol. 179, 72807290.

4. Galkin, A., Kulakova, L., Sarikaya, E., Lim, K., Howard, A., and Herzberg, O. (2004) Structural insight into arginine degradation by arginine deiminase, an antibacterial and parasite drug target, J. Biol. Chem. 279, 14001-14008.

5. Murray-Rust, J., Leiper, J., Mcalister, M., Phelan, J., Tilley, S., Maria, J. S., Vallance, P., and Mcdonald, N. (2001) Structural insights into the hydrolysis of cellular nitric oxide synthase 
inhibitors by dimethylarginine dimethylaminohydrolase, Nat. Struct. Biol. 8, 679-683.

6. Wesenberg, G. E., Smith, D. W., Phillips, G. N., Jr., Bingman, C. A., and Allard, S. T. M. (2004) Center for Eukaryotic Structural Genomics (Cesg), X-ray structure of gene product from Arabidopsis thaliana at 5G08170, agmatine iminohydrolase (to be published).

7. Baur, H., Luethi, E., Stalon, V., Mercenier, A., and Haas, D. (1989) Sequence analysis and expression of the arginine-deiminase and carbamate-kinase genes of Pseudomonas aeruginosa, Eur. J. Biochem. 179, 53-60.

8. Nakada, Y., and Itoh, Y. (2003) Identification of the putrescine biosynthetic genes in Pseudomonas aeruginosa and characterization of agmatine deiminase and $\mathrm{N}$-carbamoylputrescine amidohydrolase of the arginine decarboxylase pathway, Microbiology 149 , 707-714.

9. Santa Maria, J., Vallance, P., Charles, I. G., and Leiper, J. M. (1999) Identification of microbial dimethylarginine dimethylaminohydrolase enzymes, Mol. Microbiol. 33, 1278-1279.

10. Stone, E. M., Person, M. D., Costello, N. J., and Fast, W. (2005) Characterization of a transient covalent adduct formed during dimethylarginine dimethylaminohydrolase catalysis, Biochemistry 44, 7069-7078.

11. Lu, X., Galkin, A., Herzberg, O., and Dunaway-Mariano, D. (2004) Arginine deiminase uses an active-site cysteine in nucleophilic catalysis of L-arginine hydrolysis, J. Am. Chem. Soc. 126, 53745375.

12. Dong, Y., Chen, Y. Y., Snyder, J. A., and Burne, R. A. (2002) Isolation and molecular analysis of the gene cluster for the arginine deiminase system from Streptococcus gordonii DL1, Appl. Environ. Microbiol. 68, 5549-5553.

13. Zuniga, M., Perez, G., and Gonzalez-Candelas, F. (2002) The product of arcR, the sixth gene of the arc operon of Lactobacillus sakei, is essential for expression of the arginine deiminase pathway, Mol. Phylogenet. Evol. 25, 429-444.

14. Knodler, L. A., Sekyere, E. O., Stewart, T. S., Schofield, P. J., and Edwards, M. R. (1998) Cloning and expression of a prokaryotic enzyme, arginine deiminase, from a primitive eukaryote Giardia intestinalis, J. Biol. Chem. 273, 4470-4477.

15. Cunin, R., Glansdorff, N., Pierard, A., and Stalon, V. (1986) Biosynthesis and metabolism of arginine in bacteria, Microbiol. Rev. 50, 314-352.

16. Leiper, J. M., Santa Maria, J., Chubb, A., MacAllister, R. J., Charles, I. G., Whitley, G. S., and Vallance, P. (1999) Identification of two human dimethylarginine dimethylaminohydrolases with distinct tissue distributions and homology with microbial arginine deiminases, Biochem. J. 343, 209-214.

17. Bradford, M. M. (1976) A rapid and sensitive method for the quantitation of microgram quantities of protein utilizing the principle of protein-dye binding, Anal. Biochem. 72, 248-254.

18. Prescott, L. M., and Jones, M. E. (1969) Modified methods for the determination of carbamyl aspartate, Anal. Biochem. 32, 408419 .

19. Cunningham, J. M., and Rayne, R. C. (1998) Radiochemical measurement of NOS activity by conversion of $\left[{ }^{14} \mathrm{C}\right] \mathrm{L}$-arginine to citrulline using HPLC separation, Methods Mol. Biol. 100, 7581.

20. Galkin, A., Lu, X., Dunaway-Mariano, D., and Herzberg, O. (2005) Crystal structures representing the Michaelis complex and the thiouronium reaction intermediate of Pseudomonas aeruginosa arginine deiminase, J. Biol. Chem. (in press).

21. Jorgensen, W. L., Chandrasekhar, J., Madura, J. D., Impey, R. W., and Klein, M. L. (1983) Comparison of simple potential functions for simulating liquid water, J. Chem. Phys. 79, 926935.

22. Brooks, C. L., III, Brunger, A., and Karplus, M. (1985) Active site dynamics in protein molecules: A stochastic boundary molecular-dynamics approach, Biopolymers $24,843$.

23. Brooks, B. R., Bruccoleri, R. E., Olafson, B. D., States, D. J., Swaminathan, S., and Karplus, M. (1983) Charmm: A program for macromolecular energy, minimization, and dynamics calculations, J. Comput. Chem. 4, 187-217.

24. Cui, Q., Elstner, M., Kaxiras, E., Frauenheim, T., and Karplus, M. (2001) A QM/MM implementation of the self-consistent charge density functional tight binding (SCC-DFTB) method, J. Phys. Chem. B 105, 569-585.

25. Noh, E. J., Kang, S. W., Shin, Y. J., Kim, D. C., Park, I. S., Kim, M. Y., Chun, B. G., and Min, B. H. (2002) Characterization of mycoplasma arginine deiminase expressed in E. coli and its inhibitory regulation of nitric oxide synthesis, Mol. Cell 13, 137143.

26. Weickmann, J. L., and Fahrney, D. E. (1977) Arginine deiminase from Mycoplasma arthritidis. Evidence for multiple forms, J. Biol. Chem. 252, 2615-2620.

27. Das, K., Butler, G. H., Kwiatkowski, V., Clark, A. D., Jr., Yadav, P., and Arnold, E. (2004) Crystal structures of arginine deiminase with covalent reaction intermediates; implications for catalytic mechanism, Structure 12, 657-667.

28. Leiper, J. M., Santa Maria, J., Chubb, A., MacAllister, R. J., Charles, I. G., Whitley, G. S., and Vallance, P. (1999) Identification of two human dimethylarginine dimethylaminohydrolases with distinct tissue distributions and homology with microbial arginine deiminases, Biochem. J. 343, 209-214.

BI051591E 